\title{
“Don't just come for yourself": Understanding leadership approaches and volunteer engagement in community gardens
}

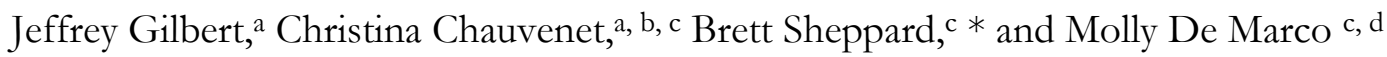 \\ University of North Carolina
}

\begin{abstract}
Submitted January 3, 2020 / Revised April 4 and April 30, 2020 / Accepted May 4, 2020 /
Published online August 4, 2020

Citation: Gilbert, J., Chauvenet, C., Sheppard, B., \& De Marco, M. (2020). “Don’t just come for yourself': Understanding leadership approaches and volunteer engagement in community gardens. Journal of Agriculture, Food Systems, and Community Development, 9(4), 259-273.

https://doi.org/10.5304/jafscd.2020.094.019
\end{abstract}

Copyright (C) 2020 by the Authors. Published by the Lyson Center for Civic Agriculture and Food Systems. Open access under CC-BY license.

\begin{abstract}
Community gardening initiatives are popular interventions for health promotion and the development of socially inclusive local agricultural models. The leadership of such gardens is critical for their long-term success and sustainability. This study describes the leadership styles of garden managers, as well as how managers recruited and interacted

a Department of Health Behavior, University of North Carolina Gillings School of Global Public Health

b Department of Maternal and Child Health, University of North Carolina Gillings School of Global Public Health

c University of North Carolina Center for Health Promotion and Disease Prevention

${ }^{\mathrm{d}}$ Department of Nutrition, University of North Carolina Gillings School of Global Public Health

* Corresponding author: Brett Sheppard, UNC Center for Health Promotion and Disease Prevention, University of North Carolina at Chapel Hill; 1700 Martin Luther King Jr. Boulevard, CB\# 7426; Chapel Hill NC 27599-7426 USA; +1-571447-8950; brshep@email.unc.edu
\end{abstract}

with volunteers. Thirteen community garden managers were interviewed, and 48 community garden volunteers participated in six focus groups. Transcripts were coded with Dedoose software using a conventional content analysis, which led to the development of thematic clusters in consultation with a qualitative data expert. During the analytic process, codes were refined and added, and three themes were identified: managers struggled to recruit and retain volunteers capable of maintaining gardens; garden managers' leadership styles were either collaborative or directive; and garden participants emphasized managers' organization and openness to ideas. Leadership styles varied among managers, and participants acknowledged and appreciated elements of both leadership styles.

\section{Funding Disclosure}

This manuscript was developed with funds provided by the U.S. Department of Agriculture's (USDA) Supplemental Nutrition Assistance Program Education (SNAP-Ed), award number 00036242 . The USDA is an equal opportunity provider. 
More research is needed on the impact of leadership styles on other measures of garden success.

\section{Keywords}

Community Gardens, Leadership, Volunteer

Engagement, Qualitative Research

\section{Introduction}

Participating in community gardens has been associated with several health-related benefits, including increased access to, and consumption of, fresh fruits and vegetables (McCormack, Laska, Larson, \& Story, 2010; Patel, 1991), as well as reduced risk of chronic disease (Boeing et al., 2012). Participating in community gardens is typically defined as volunteering in garden planting, maintenance, or operations (Booth, Chapman, Ohmer, \& Wei, 2018). Beyond fruit and vegetable consumption, research on community gardens has explored how gardens build community capacity and cohesion, bridging communities of diverse races, ethnicities, and ages (Glover, Parry, \& Shinew, 2005; Teig, Amulya, Bardwell, Buchenau, Marshall, \& Litt, 2009). Such interventions may prove especially helpful in ensuring that food systems are socially inclusive and foster equity, social integration, and the "generous creation of natural human capital" (Macias, 2008).

Gardening initiatives are one of several policy, systems, and environment (PSE) strategies supported by SNAP-Ed, an evidence-based nutrition education program that complements the Supplemental Nutrition Assistance Program (SNAP) (U.S. Department of Agriculture Food and Nutrition Service [USDA FNS], n.d.). Conventional nutrition education programs typically engage a limited number of individuals per session and are often hampered by recruitment and attendance challenges, lowering their potential reach (Haynes-Maslow, Osborne, \& Pitts, 2018). PSE interventions, on the other hand, are designed to "make the healthy choice the easy choice," and influence the broader community (Leung et al., 2013). In a 2018 study of SNAP-Ed implementing agencies, garden-based interventions were the most frequently cited PSE education strategy in rural communities (HaynesMaslow et al., 2018).

Previous literature has explored the processes in community gardens that contribute to social cohesion and increased community capacity, but this research has not explicitly addressed the influence of individuals in positions of power on community garden goals and systems (Alaimo, Reischl, \& Allen, 2010; Egli, Oliver, \& Tautolo, 2016; Hartwig \& Mason, 2016; Lanier, Schumacher, \& Calvert, 2015). It is well understood that leadership is critical to the success of any community-based project (Ceptureanu, Ceptureanu, Luchian, \& Luchian, 2018). Far less understood-given the paucity of relevant results in a literature review-is how different qualities of leadership styles can lead to vastly different experiences by program participants (Patton, 2009), even in a relatively simple program. When 'leadership' is discussed in relation to community garden initiatives, the discussion focuses on the benefits the community garden setting provides in the development of leadership characteristics among members, not on how leadership quality influences garden style and measures of success.

However, the quality of leadership in community garden settings is surely an important factor in encouraging and sustaining broad participation by community garden members, members who in turn can reap the myriad benefits of community garden participation. The SNAP-Ed Toolkit identifies 'Champions'_-....people who provide sustained and often charismatic leadership..."-as one of its core indicators in measuring program success and sustainability (SNAP-Ed Toolkit, n.d.).

These leaders fill a more challenging and nuanced role than generally conceived: they possess deep knowledge of the community, tap into local resources, and unify direction in the interest of shared ownership (Aoun, Shahid, Le, \& Packer, 2013). The unique perspectives that leaders bring are especially important because garden projects tend to be specific to their communities. For example, a garden located in a faith community might function quite differently and attract different participants than one based at a school, making it difficult to generalize lessons learned.

This paper aims to understand who leads community garden efforts, as well as how they lead these efforts in order to broaden the understanding of some of the ways that community gardens func- 
tion. By utilizing qualitative methods, the researchers explore the conditions and processes that are unique to each community's organization. Understanding attributes of garden management is critical to better documenting different approaches that could facilitate the sustainability of these programs.

\section{Methods}

The University of North Carolina Center for Health Promotion and Disease Prevention (HPDP) is an implementing agency for SNAP-Ed that supports SNAP-Ed initiatives in six North Carolina counties. Part of supporting these initiatives includes providing training and technical assistance for 18 community garden projects. Of the 18 , three were targeted at engaging youth, three were situated in senior centers, three were situated with faith-based institutions, and nine were for general use in a park or common community area. While SNAP-Ed constrains some operational and financial decisions, HPDP strives to involve and empower participants by using community-engaged research principles. Recognizing that each of the gardens is unique, HPDP allows the community to shape the garden's mission and goals, as well as its organizational processes. At each garden, a community member serves as a manager who recruits and organizes garden volunteers, coordinates logistics, and facilitates data collection on participation and harvest totals. This community garden manager is always a person who had prior experience working with the organization or group the garden is formed around and is often the leader of that organization or group. At some gardens, the role of community garden manager changes hands at irregular intervals. For their efforts, garden managers receive a small stipend.

Because the community garden manager is the one person at each garden who has regular contact with the project manager at HPDP and the one person who is paid to help the garden run, he or she wields a great deal of power in shaping some pieces of the garden project. To encourage more equitable distribution of power, the project manager at HPDP participates in meetings with each community garden group so as to hear from others and try to facilitate group decision-making on fundamental decisions determining how the garden will function. However, those occasions are intermittent, and the majority of the time the garden manager sets direction with as much or as little input from the community has his or her management style dictates. This power structure-which may not be dissimilar to the majority of community gardens-makes understanding leadership styles very important.

Between August and October 2017, trained researchers from HPDP (including authors CC, $\mathrm{BS}$, and MDM) conducted semi-structured interviews with garden managers $(n=13)$ and focus groups with garden participants (48 individuals in six focus groups). Interviews and focus groups lasted between 60-90 minutes. Semi-structured interviews were held with garden managers due to the smaller number of garden managers (only one or occasionally two managers per garden compared to an average of 15 or more garden participants per garden). Each of the community gardens was represented either through garden manager interviews or through gardener participation in focus groups. Focus groups were conducted throughout the project implementation region to allow for participants from different counties to participate. Table 1 shows demographic characteristics of participants from the interviews.

Interviews and focus groups were mostly conducted in English. One garden had a majority of Spanish speaking participants, so the manager interview and focus group were conducted in Spanish by one of the study co-authors (CC) who is fluent in Spanish. Interviews and focus groups were audio recorded with participant permission, then transcribed and de-identified. Spanish language transcripts were translated into English for analysis. Researchers asked managers specifically about garden operations and organizational structure. Because garden managers were tasked throughout the season with collecting quantitative data on garden participation and garden yield, these interviews were an opportunity for managers to describe the successes and shortcomings of their gardens in ways that were not captured by these measures. During the focus groups, on the other hand, researchers encouraged garden participants to speak freely about challenges and frustrations in the garden, as well as successes, without the garden 
manager in attendance. A sample of key focus group and interview questions is available in Table 2. Participants received US $\$ 25$ for their time.

Prior to conducting this secondary analysis, the first author had limited contact with these data; he had no role in data collection, whereas the other authors took part in developing the interview guides and collecting data. Upon receiving the transcribed data, JG read each transcript twice, utilizing a conventional content analysis approach with the aim of understanding the data and identifying potential research questions (Hsieh \& Shannon,

Table 1. Participant Demographic Characteristics

\begin{tabular}{|c|c|c|c|}
\hline Characteristic & $\begin{array}{c}\text { All } \\
(n=61)\end{array}$ & $\begin{array}{l}\text { Focus Group } \\
\quad(n=48)\end{array}$ & $\begin{array}{c}\text { Garden Manager } \\
\quad(n=13)\end{array}$ \\
\hline \multicolumn{4}{|l|}{ Gender, n (\%) } \\
\hline Male & $12(19.7)$ & $8(16.67)$ & $4(30.8)$ \\
\hline Female & $49(80.3)$ & $40(83.33)$ & 9 (69.2) \\
\hline \multicolumn{4}{|l|}{ Race, n (\%) } \\
\hline American Indian or Alaska Native & $5(8.9)$ & $4(8.89)$ & $1(9.1)$ \\
\hline Asian & $2(3.6)$ & $2(4.44)$ & $0(0)$ \\
\hline Black or African American & $38(67.9)$ & 31 (68.89) & $7(63.6)$ \\
\hline White & 9 (16.1) & $8(17.78)$ & $1(9.1)$ \\
\hline Mixed Race & $2(3.6)$ & $0(0)$ & $2(18.2)$ \\
\hline \multicolumn{4}{|l|}{ Ethnicity, n (\%) } \\
\hline Hispanic/Latinx & $6(10.2)$ & $4(8.33)$ & $2(18.2)$ \\
\hline Not Hispanic/Latinx & $53(89.8)$ & $44(91.67)$ & $9(81.8)$ \\
\hline \multicolumn{4}{|l|}{ Age, mean (SD) } \\
\hline & $53.1(16.1)$ & $52.9(17.5)$ & $53.6(9.3)$ \\
\hline
\end{tabular}

Note: Demographics were collected by self-report in a short survey prior to interviews and focus groups. Missing values are due to participants leaving demographic characteristics blank. 5 values were missing on race, 2 on ethnicity, and 3 on age.

\section{Table 2. Key Interview and Focus Group Guide Questions ${ }^{a}$}

\begin{tabular}{ll}
\hline Interview Guide & Focus Group \\
\hline What does a successful community garden look like? $^{b}$ & $\begin{array}{l}\text { What did you think volunteering at the community } \\
\text { garden would be like? How similar/different is this from }\end{array}$ \\
\begin{tabular}{ll} 
what your volunteering experiences have been like? \\
\hline In what ways has the community garden you work with been
\end{tabular} & $\begin{array}{l}\text { Do you feel like you have a say in how the garden } \\
\text { works? }\end{array}$ \\
\hline How do you feel about your experience with the garden? & $\begin{array}{l}\text { Do you feel like you can make suggestions about what } \\
\text { is happening in the garden? }\end{array}$ \\
\hline
\end{tabular}

What are your existing needs at the garden? Were there needs, throughout the season that weren't met? These needs could be monetary, equipment for the garden, or any other type of assistance.

Based on your answer just now (reference above answer), how, if at all, did these unmet needs affect the garden?

How do you recruit volunteers for the garden? Do you feel you have enough volunteers to maintain the upkeep of the garden?

What is your relationship with the volunteers of the garden? How, if at all, has that changed over time?

a These questions do not constitute the full interview guide, but rather a selection of key questions. Probes were included with the guides but are not presented here for brevity.

b Question also asked during focus group. 
2005). With no predefined research questions, this inductive approach enabled JG to propose thematic clusters that would structure the codebook. Such a methodology aligns with HPDP's research approach by allowing the perspectives and knowledge of the participants, rather than the preconceived theoretical perspectives of the researchers, to drive analysis. JG developed a set of descriptive codes, including codes categorizing the tasks of garden managers, barriers to garden success, and managers' characterization of participants. JG conducted analysis using Dedoose qualitative software (version 4.7, SocioCultural Research Consultants, Los Angeles, CA). Analysis was iterative; after coding several transcripts JG added codes on explicit and implicit leadership styles to the codebook, which would later inform the final analysis. At this point, the final research questions guiding this secondary analysis were clarified (see Table 3).

Following the coding process, data were organized into a matrix to compare several key descriptive and interpretive themes without disaggregating quotes from their speaker and context (Maxwell \& Miller, 2008). An iterative process of writing, revising, and revisiting the data followed to further explore and connect those passages deemed most pertinent to the research questions.

\section{Results}

In the interviews with garden managers, we identified important themes about volunteer recruitment and retention, as well as managers' leadership styles. While we present our results in an organized manner, which could suggest that participant perspectives can be cleanly separated into distinct categories, the data demonstrate a spectrum of experiences. We utilized pseudonyms for garden managers so that individual perspectives and ideas can be traced throughout the manuscript. The reader should not attempt to develop any singular notion of how a garden might best operate from these perspectives. Because the individual voices of the managers are important to understanding this paper, Table 4 gives a brief overview of the inter-

\section{Table 3. Final Research Questions}

Who participates in the community garden?

In what ways do garden managers ascribe meaning to volunteers based on their age?

In what ways do different garden managers' leadership styles inform their ability to attract and retain volunteers?

How do managers' leadership styles shape their interactions and relationships with other gardeners?

Table 4. Garden Manager Pseudonyms and Garden Characteristics

\begin{tabular}{|c|c|c|c|}
\hline $\begin{array}{l}\text { Garden Manager } \\
\text { (Pseudonym) }\end{array}$ & Organization Type & Garden Style and Size & $\begin{array}{c}\text { Average number of } \\
\text { garden participants } \\
\text { per month, } 2017\end{array}$ \\
\hline Jasmine & Senior center & $\begin{array}{l}\text { Approx. } 1 / 2 \text { acre in rows }+ \text { three } \\
\text { garden boxes }\end{array}$ & 4.33 \\
\hline Shawn & Faith-based & Approx. $1 / 3$ acre in rows & 8 \\
\hline Natalie & Senior center & 3 large garden boxes & 7.5 \\
\hline Jane & Faith-based & 4 garden boxes & 7.67 \\
\hline Kayla & Public housing & Approx. $1 / 4$ acre in rows & 6.17 \\
\hline Zasha and Maya & Housing community & 8 large garden boxes & 32.5 \\
\hline John & Faith-based & 3 garden boxes & 5 \\
\hline Corey & Community development corporation (CDC) & 3 large garden boxes & 5.67 \\
\hline Tasha & Public housing & 8 garden boxes & 12.33 \\
\hline Jeanette & Senior denter & 4 large garden boxes & 6.17 \\
\hline Ryan & Community garden nonprofit & 16 garden boxes + fruit trees & 12.33 \\
\hline Jerry & Community development organization & Approx. 1 acre in rows & 10.33 \\
\hline
\end{tabular}


view participants whose words are used. An overview of the themes that emerged follows.

\section{Managers Struggled to Recruit and Retain Volunteers Capable of Maintaining Gardens}

When asked at the beginning of their interview to describe their community garden, managers either discussed the physical characteristics of the garden — the size of beds, the crops growing-or, more frequently, discussed who volunteered in the garden's upkeep and maintenance. By centering their description of the garden on these volunteers, the managers emphasized the pivotal role that labor plays in day-to-day operations. Managers rely heavily on community involvement and volunteerism, and the individuals that showed up consistently shaped their experience of the garden.

Managers discussed both volunteers and garden yield even though they were not explicitly prompted to do so. However, these are the two quantitative measures that their role requires them to monitor. Qualitative interview questions, including "What does a successful community garden look like?" and "In what ways has the community garden you work with been successful?" were constructed to allow managers to provide a richer sense of how managers' conceptions of their garden's objectives can differ from established community goals.

Most managers reported that they had difficulties recruiting enough volunteers, and that this was an impediment to their garden's productivity. It should be noted, though, that their commentary suggests that simply keeping track of the average number of volunteers was an insufficient metric to describe if volunteer efforts were helpful. 'Kayla' was a manager of a garden that partners with the local church. Unlike most managers, Kayla was typically able to recruit volunteers, but conceded that the distribution of labor between participants and over the course of the growing season was often inconsistent:

Nine times out of 10 you get a couple of volunteers who do the hardest work and then you, you know. They're kinda like worn out and in the end of season you really have nobody but you.
Garden managers' perceptions of their volunteers' age and physical abilities often reflected how much importance they ascribed to garden yield (versus other less quantifiable outcomes.) Several of the gardens affiliated with senior centers or churches are maintained by older volunteers. In these settings, garden managers expressed different values related to how the age of their volunteers contributed to work ethic and work culture. 'Jasmine,' the manager of a garden located at a senior center, attributed the seniors' enthusiasm for helping in the garden to generational norms around farming and gardening:

They're old schoolers, this is what they know, this is how they grew up, so they seem more eager to be involved and participating.

Enthusiasm alone, however, was often viewed as insufficient for garden success. Managers admitted that a large number of older volunteers might not be optimal for garden upkeep. Several mentioned that participants' age was often a constraint on their ability to participate, but that these volunteers could still contribute meaningfully to the garden operations: "you know, some of them would just come out and I was like, just hold the hose." The seniors in the community may love and appreciate the garden, but as 'John,' a manager at a faithbased garden, glibly puts it, "they just ... they're too old to come out and work it."

According to the managers, seniors often had gardening knowledge and experience that made them invaluable even if they provided limited physical labor. 'Shawn' is one of the managers who shared this perspective. He noted that:

I'm learning every day from different ones, that there's a guy, um older man that comes down there. He don't work in the garden but he just comes down there, and he give me pointers.

While some managers noted the positive contributions of their older volunteers, nearly all the managers and participants admitted that having more young people involved would be a boon to their garden, as their physical strength and mobility 
would allow them to contribute more significantly than older participants. Managers described how they depend on the younger volunteers to perform more laborious tasks, and that they were more comfortable in hot weather. Age, however, was not always viewed as a proxy for the ability to execute garden tasks. 'Corey,' who manages a garden with participants who are veterans, mentioned she has a young assistant who is instrumental in helping with planning and logistical coordination. She notes that those who collect SNAP benefits, but especially young people, "need to have some seeds. They need to have soil. They need to be involved in the community garden project." Corey repeatedly emphasized the educational benefits that youth gain from the garden and that the garden benefits from the intellectual contributions of these young volunteers and not just their physicality.

While positive perceptions of youth participants were widely held amongst managers, two garden managers described young garden volunteers negatively, claiming that they were lazy or irresponsible. John provided brief responses during his interview, often replying only in a few words and declining to elaborate when pressed further. In his limited responses, he frequently returned to his belief that young people did not want to work:

...you know, young people, young men don't wanna work for some reason [laughter]. I don't know why, but, uh, they just refuse to work.

This characterization, though contrary to that shared by other managers, might be a reflection on recruitment challenges. John noted that it is tough to engage young people who are working in paid positions full-time, and who may not want to volunteer without the promise of compensation.

Certain gardens have an intentional focus on youth development or youth empowerment, and managers of these gardens were keenly interested in ensuring that young people actively participated. One such manager, 'Jerry,' explained that the potential for financial opportunity that gardening provides is an impetus for teens to get involved. He reported that he hopes to empower the youth in his program so that they are motivated to become agricultural entrepreneurs.

\section{Garden Managers' Leadership Styles Were Either Collaborative or Directive}

Garden managers described their leadership style in a way that was consistent with either collaborative or directive approaches. Those who took a collaborative approach emphasized their attention to community members' needs and desires. These leaders tended to be flexible and incorporate volunteer suggestions, allowing those opinions to shape how the garden was operated throughout the growing season. Those managers who tended to lead in a directive way, on the other hand, utilized language that centered their own vision for the garden. Directive leaders tended to describe garden volunteers in terms of how much they contributed to or hindered the realization of their vision. This distinction was at least partially predicated on gender: the three male managers were best categorized as directive leaders, while nine of the ten female managers were collaborative.

These interpretive categories should be viewed as frameworks for unpacking intra-group distinctions, rather than monolithic or exclusive typographies. These categories were constructed following descriptive coding rounds incorporating parent codes like "Motivation for Gardening" and "Garden Manager Tasks." The terms collaborative and directive might best be viewed as shorthand for the relationship between how a manager viewed their garden and what they felt they did during daily management. For example, those whose motivation for gardening was coded as "obligation to help others" tended to overlap with the task of "mediating conflict," - a collaborative style-whereas a motivation of "economic opportunity" or "transactional give and take" might overlap with "telling people what to do"- a directive style. Not all managers fell neatly into one or the other leadership style; a few managers offered anecdotes illustrating that they embodied both styles. Below is a summary of how garden managers described their position in the garden, relative to their volunteers both young and old.

\section{Collaborative Leaders}

A common way in which managers acted as collaborators was through allocating produce after harvest. When individuals - seniors and/or those with disa- 
bilities, in particular - were unable to help maintain the garden, collaborative managers called attention to how they still shared produce from the garden with those individuals. 'Jeanette' notes that the garden she managed would allow anyone to come to the garden and take food, even if they did not participate.

You know I do have people come in and, um, and just wanna come pick something, and um, and I've had people walk in, and I don't really know them, that's all they came for. They'll ask, "Do you have anything in the garden that I can pick and have?" And I let them out there.

This sharing of garden produce was presented as a wholly charitable act, with several managers expressing this altruistic sense of giving back to others as a significant, satisfying reason why they chose to manage the garden in the first place.

A few managers, such as Jasmine, recalled how they sought to empower younger people to take garden produce home to older relatives, thereby enhancing the impact of the garden while allowing the young people to position themselves as helpers and providers:

So, what I always tell them you always have someone younger working, someone in your house that's younger than you...I always say when you come to the garden, don't just come for yourself. When you come out here, first of all I want you to go by the senior citizens, put your name down, whatever you come to get it I want you to take half back out there, and then once it gets out there it'll get distributed.

Like Jeanette, Jasmine's insistence that young people "don't just come for yourself" suggests an embedded sense of altruism and a collective effort in her leadership style. Under her guidance, those who volunteer, especially those who are young and capable, should be seeking more than their own satiation. Beyond the tangible (re)distribution of fruits and vegetables, Jeanette's instructions serve to bring generations together to share in the benefits of the garden.
Several of the managers viewed their role as more than just coordinating the logistics of the garden. These managers emphasized that their position empowered them to build trust and bring garden volunteers together, building social cohesion and connection. 'Tasha' saw her role as a connector, and shared that while she felt the garden's output of produce was important, it was also significant that she could build relationships between people:

I've thought about the statement, 'You have an uncanny ability to attract people.' I don't think it's my ability to attract people. I think it's my ability to want to identify folk. I have a sense that I know who has similarities, and I can connect people... And then that person is connected. And I have this through connection, I can connect. I like the connection. And... and showing people their own strength.

Unlike many of the other garden managers, Tasha expressed fewer issues attracting and retaining volunteers. Her words suggest that it is incumbent on a leader to not simply coordinate participants as a requirement, but to actively want to encourage volunteers and to show them "their own strength."

'Jane' is another collaborator who, as both the pastor of a church and the manager of the congregation's on-site garden, expressed that she felt the garden served a much larger purpose than its agricultural yield. She claimed that the garden had "given us a foundation from which we can now identify other needs in the community and see ourselves as agents." Unlike several managers who viewed recruiting youth as a means to accomplish more garden work, Jane saw the role of youth as central to their own empowerment, remarking that,

as the young people move away and...pursue other things it's a skill set they'll take with them. An experience that they'll take with them that they could potentially utilize wherever they are in the future.

Throughout her interview, Jane discussed how her personal vision for the garden had not been 
wholly fulfilled - that the garden was not as productive and aesthetically attractive as she would like. Yet, while she recognized a difference between her personal expectations for the garden and its reality, she frequently returned to its benefits for the youth who participate. In providing a physical space at the church, she felt that she had facilitated a sense of community that extended beyond the congregation. That Jane was able to separate her goal from these other favorable outcomes is a hallmark of a collaborative leadership style.

\section{Directive Leaders}

A few managers mentioned that their role sometimes required them to be stern or strict when participants did not subscribe to assumed group norms, or when overzealous volunteers imposed their own ideas about how the garden should operate. While some imposition of collective rules may be expected for all managers, a key attribute of directive leaders was this lack of flexibility when garden participants suggested changes throughout the season. The managers who presented stories of scolding participants tended to believe that their personal investment in the garden granted them the power to unilaterally approve or deny such suggestions. 'Shawn' remarked, 'We have some that come out there trying to take over, but I just tell 'em, you know, this is my pride, this is my joy. So, if you wanna help? Get in line." He recognized, however, that the role of a volunteer coordinator comes with a set of challenges. Shawn noted that because participants are not paid, there are limits to how much clout his word holds:

So, if you don't wanna do it you don't have to! You're not getting paid to do this! You don't have to listen to me, but you not gonna come out here and tell me what I'm doing wrong! Let me find out for myself what I'm doing wrong. So, if it's wrong, it's wrong!

Throughout his interview, Shawn returned to his own education, how the individuals around him—specifically those older than him—had taught him. His words frequently centered on what he has gained from the garden, rather than what the participants had gained. Because he views the garden as his "pride" and "joy," those who resisted his vision of the garden were seen as unwelcome.

Shawn was not the only manager whose selfinterest and engagement in the garden directly affected his management style. When asked if she had enough volunteers, another manager, 'Anna' replied:

I do, cause one I like to be down there by myself. Which is probably selfish, but I like it that way... I'm real selfish when it comes to that garden, overprotective of it. So, yeah. We can use more, yes.

Anna, then, held two conflicting opinions: she wanted to have direct control of the garden, but also knew that the garden could use more support. This is made manifest in her approach to leadership:

...you don't wanna put yourself too far out there but it works out pretty well once you give them how you want the place to be, once you get them the information about what to do, what not to do then sit back. But I don't like to sit back, I like to help, so I stand side by side.

While her words initially suggest a sentiment of collaboration and egalitarianism, a closer reading reveals that her leadership style was predicated on her desire to be closely involved in the aspects of the garden she found most compelling. Anna admitted that it was "probably selfish" to center her own approach to the garden, but also recognized that it "works out pretty well" to marry this active engagement in garden operations with a directive leadership style.

The garden that Jerry manages is one of several projects operated through his youth empowerment nonprofit. Jerry's garden functions quite differently from the others, and he did not express having difficulties recruiting participants. Jerry, however, was also very strict in how he runs and operates his garden:

Guidelines, I follow the guidelines, on the program. And through the guidelines, then there's a, I got older people, younger people 
out there. So, there's only one way, there's one way to do this thing and that's, that's the program dictates the program. The program, not me! But the program does, but I developed and designed the program, okay...I'm in, I'm in charge, that's why I'm sitting why talking to you. So, at the end of the day, if you attend my garden, I'm a give you your instructions for the day.

Jerry clearly defined the goals of his garden, with a vision that was decisively focused on the economic opportunity that gardening and smallscale farming offers. Emphasizing that he is "in charge" and that "there's only one way to do this thing," Jerry's reliance on the "guidelines" aligns with his rather narrow vision of success. He has made a priori assumptions about how the garden will operate and is less willing to change during the season, or even over the course of one day. With tens of thousands of dollars of grant funding and robust agricultural yield, the garden that Jerry manages has been undoubtedly successful, complicating any singular notion of how gardens should be operated.

Tasha, who emphasized her role as a connector and unifier, also occasionally had to deal with conflict. In her interview, she shared an anecdote of how she responded to older women who were possessive of the garden operations:

There's about four older women, elderly women, that was very possessive when the garden first started. And I think they thought, every year 'this is mine.' And uh, (I told them) 'You have to share. It's not yours.' They became very, oh gosh, they were... They had such ownership. They [said], 'Well, I'm just not gonna participate' ...I feel bad because I want them to be able to share and it's... Everybody should have an opportunity. You know? You know, I every year, I go knock on their doors, 'Please come back.' But what I do is, I give them vegetables still out of the garden.

In her story, Tasha was firm in her words but, consistent with her self-description as one who likes connection, she was firm in the spirit of unify- ing the garden. She recognized that the women had a strong sense of ownership of the garden's operations but wanted to extend this feeling of belonging and ownership to everyone. Tasha explained that she gave out produce as a peace offering so that the older women could benefit from the garden's output, but she also strove to express unity by helping the older women feel a shared sense of contribution. It might be most useful, then, to view this example as showing how a manager demonstrating a collaborative leadership style does not indicate that the manager is passive in the face of conflict.

\section{Garden Participants Emphasized a Need for Managers' Organization and Openness to Ideas} In focus group discussions, garden volunteers cited the benefits of having a leader who was organized and "on top of things". Many acknowledged that they would defer to the manager when it came to day-to-day operations if they felt as though the leader was inclusive of others' opinions and contributions. For example, one volunteer expressed that an effective leader would recruit individuals even if they may not be physically capable of gardening:

I think that that they need to come up with different ideas that the person is heading it that you can give to them and then that way we can go out and kinda press it out throughout the community and find out what would make people want to come... You may can't bend over, you may can't weed, you may can't do certain things but it to me it would be more fulfilling if I know my contribution may be small but the benefits at the end are worth it.

This perspective aligns closely with the perspective revealed in the manager interviews, demonstrating that participants do not necessarily see garden yield as the sole marker of a successful garden. These volunteers believe that the garden manager should "find out what would make people want to come," to the garden, suggesting that community opinions should hold a great amount of clout from the beginning. Participants were inspired by leaders who cared for the overall wellbeing of the community: "I was mostly impressed 
by the [manager] and her community spirit and...her desire to just try to do something that's gonna benefit everybody."

One participant suggested that the mere presence of a community-oriented space enabled individuals from different backgrounds to join together:

There's a lot of times that adults and teenagers or children don't get together to learn certain things, certain things that elders can teach younger children. Yes, it is about growing vegetables that is healthier for us that don't have pesticides and things like that, but I feel like it can also be an effort to learn different things.

The speaker recognized that individuals are often limited in their contact with those of other generations, and that the garden is a site of knowledge transfer and more importantly a site of possible intergenerational friendship.

Several participants described how their garden's manager solicited opinions and feedback, but they had little confidence that these were truly taken into consideration. When asked if she felt that she had "a say in the way that the garden works?" one participant remarked "Oh, yeah, I mean, I can say anything I want, not that it'll happen." A volunteer in another garden was unsure if she had a platform in any form.

Zasha [garden manager] is always fighting, and I know that perhaps she is the voice right now. And perhaps, if she says 'I am going to do that' we will be with her. We will say "yes, Zasha," because she will explain [it], she will give [us] the information, and we will be there... but I can't say for sure that I have a voice or that I don't have a voice.

Of note, both of these participants worked alongside managers who had described their leadership style as collaborative, indicating a disconnect.

Some participants expressed frustration regarding their leader being disorganized or felt the vision of the garden was "piecemeal." In one garden where there was very little yield, a participant claimed there was a need for an explicit "hierar- chy," suggesting that there is a role for directive leadership in some community gardens. A longtime gardener expressed that a lack of communication and centralized decision-making impeded her ability to contribute meaningfully or share her knowledge with others. Other unsuccessful gardens were led by leaders who did not involve community members in the planning process, or who waited until it was too late in the growing season to try to recruit participants.

I think that's one of the things that we have to really come to who's doing the planning. I don't know how some of the people have their gardens but we were just approached kinda like okay it's time to plan in May we were approached to do a garden in April so we didn't have time to do a lot of planning.

To this end, participants wanted their opinions to be incorporated early and often and grew frustrated when they perceived calls for collaboration as empty rhetoric.

These participants were critical of their leaders when they felt like their contributions were not valued or when they felt like their leaders did not find ways to incorporate all volunteers.

\section{Discussion}

Community gardens are an effective intervention that can influence a broad range of factors related to participant health and well-being, such as the adoption of healthy behaviors including fruit and vegetable consumption (Boeing et al., 2012; McCormack et al., 2010; Patel, 1991; Quested, Thogersen-Ntoumani, Uren, Hardcastle, \& Ryan, 2018). Community gardens can also have a positive impact on upstream determinants of health, such as community cohesion (Bateman et al., 2017; Firth, Maye, \& Pearson, 2011), mental health (Adevi \& Lieberg, 2012; Whatley, Fortune, \& Williams, 2015), social capital, and civic engagement (Glover et al., 2005; Teig et al., 2009).

While community gardens are effective interventions for health promotion, they can be difficult to sustain, and the factors influencing long-term success have received little attention in published studies. Examining the influence of leadership 
characteristics of garden managers on how a community garden is experienced by participants has the potential to help elucidate one important factor in community garden sustainability.

The results of this qualitative analysis offer insights into how garden managers' goals and the perspectives of their volunteer base may shape garden operations. In the interviews, directive managers frequently described age as a qualifying attribute of volunteers and often viewed garden harvest yield as a primary, if not exclusive goal. Volunteers who were older or who had disabilities were often perceived by managers as the recipients of produce, with younger more able-bodied participants viewed as the primary source of labor. Collaborative managers who held a more expansive view of their role as leaders-vocalizing benefits of community cohesion and connectedness - tended to see intergenerational collaboration as an important goal in and of itself and emphasized the value of older volunteers' horticultural knowledge. To these managers, young people were viewed as more than just able-bodied workers. They were also seen as foundational assets to form connections within the garden and as a bridge to the surrounding community.

Leadership styles fell roughly along gender lines, which is in line with previous research on gender roles within gardens. Parry, Glover, and Shinew (2006) have demonstrated that women are usually more comfortable thinking of themselves as co-leaders with others, seeking cooperative, teamoriented approaches to management. Their study was limited to interviews with female gardeners, and noted the perception that men were more work-oriented, and "harder to work with as far as flexibility." Interviews with male managers during the present study are consistent with those findings; respondents like Jerry and John offered garden visions predicated on the production of a large amount of produce, and a volunteer base that works hard. In general, these male managers emphasized an authoritative approach to leadership and expressed less emphasis on relationshipbuilding than their female counterparts.

Short (2012) also explored community gardens operated by universities, though these community gardens were on or near universities, unlike in our study. Short identified a "shared leadership" approach as a characteristic of successful community gardens, which is similar to the "collaborative leader" approach we identified. Our research builds on Short's work by expanding beyond university settings, as most of the gardens in this study were in rural areas. Since gardens in rural settings may not benefit from a consistent supply of volunteer labor from students and faculty as described by Short, leadership styles may hold a more important role in the sustainability of gardens and the maintenance of adequate "staffing" by volunteers.

Given that community gardens provide a diverse set of potential benefits to participants, it is necessary to consider how leaders can be best supported, both internally and by external partners, to ensure the sustainability and long-term success of garden projects. One method is for universities to support garden initiatives during implementation by providing funding and technical support, facilitating meetings, or encouraging leaders to network with other advisory groups, community-based organizations, or food policy councils (Firth et al., 2011; Haynes-Maslow et al., 2018). When external stakeholders provide support, they must recognize the autonomy of partner organizations to determine their own goals and structures, and not impose any singular model of best practices.

Our findings might also inform future studies on conflict mediation or intergenerational communication; community gardens are an important place to bring together diverse people from a community, but this convergence also means managing different opinions and perspectives. There is a widely stated need for more volunteer labor, especially in gardens in senior living communities, and implementing agencies should consider how to facilitate connections between different volunteer sources. Some garden managers can benefit from skills training to help augment their natural leadership skills and styles, but trainings should be conducted in a way that supports the community's goals rather than impeding upon members' selfdeterminism.

\section{Limitations}

This study has limitations. Participants were aware that staff members from HPDP were conducting 
the interviews, and as such, there may have been social desirability bias; participants may have overemphasized the successes of the garden or shared more of what they thought the interviewers wanted to hear. Interview and focus group participants may have been reluctant to share anecdotes of personality clashes, and thus this would not be captured in our analysis. Managers may have felt hesitant to report challenges in their gardens because they knew that the interviewers were from the institution where they receive their funding. Research staff tried to address this issue up front by emphasizing anonymity in responses and the desire for critical feedback. Although the HPDP staff member who manages the community garden project and regularly interfaces with garden participants did not participate in data collection, managers may still have restrained their answers. Participants did, however, share several concerns and criticisms about the garden, suggesting that they felt comfortable being honest with research staff.

As an outsider to HPDP, as well as to the individual gardens and the communities in which they were situated, the position of JG presented both challenges and opportunities. The distance from the data prevented JG from contextualizing the attributes and perspectives of interviewees outside of what exists in their transcribed speech. The goal and structure of data collection was within a community-driven research framework; however, this particular analysis was unable to follow those methodological principles as closely given the fact that the analyses were performed by an outside researcher without room for community feedback and input. This separation, however, also affords an ability to critically assess the university's role in facilitating and supporting communities. JG collaborated with co-authors who provided relevant history and current status of HPDP's work with the community gardens, which further grounded him in this analysis.

\section{Conclusion}

This qualitative study explored the perspectives of community-based managers of SNAP-Ed-funded community garden projects regarding volunteer engagement and leadership style. This study identified two main leadership styles, collaborative and directive leadership, which were often elastic and could be exhibited by the same manager at different times. The central themes explored in this paper-age and leadership—were identified during an iterative process of memoing, coding, and writing, but were not included in the initial research aims or interview guides prior to data collection. Future studies might consider how these themes, as well as other findings from the data surrounding community cohesion and feelings of ownership in the planning process, could be explicitly incorporated into evaluation planning for garden programs to better expand upon these preliminary findings. Furthermore, future research should examine how leadership styles impact traditional measures of garden success such as nutrition behaviors, garden yield, and volunteer engagement.

Haynes-Maslow et al. (2018) suggest that a best practice for ensuring long-term sustainability of SNAP-Ed PSE interventions is to frequently communicate "short-term wins" with the community. By visually demonstrating the influence of such interventions on behavioral and systems change, technical assistance agencies help to generate community buy-in so that benefits do not exist in a silo, solely benefiting those who choose to participate regularly in the garden. Rather than only measuring success by pounds of food grown, garden managers should be advised to frequently report the "short-term wins" of community cohesion and unity that they can achieve through collaborating with their volunteers in the garden.

\section{Acknowledgments}

Thanks to Ramine Alexander, Bridget Gallagher, William Kearney, Maria Koutlas, Esme MerrittDorosin, Alvaro Nava, Nasir Siddique, Claire Sadeghzadeh, Daniella Uslan, and Tiki Windley for data collection. Thanks to Paul Mihas for recommendations on interview and focus group guides. Thanks to Clare Barrington for her guidance and methodological support during the manuscript's development. 


\section{References}

Adevi, A. A., \& Lieberg, M. (2012). Stress rehabilitation through garden therapy: A caregiver perspective on factors considered most essential to the recovery process. Urban Forestry \& Urban Greening, 11(1), 51-58. https://doi.org/10.1016/j.ufug.2011.09.007

Alaimo, K., Reischl, T. M., \& Allen, J. O. (2010). Community gardening, neighborhood meetings, and social capital. Journal of Community Psychology, 38(4), 497-514. https://doi.org/10.1002/jcop.20378

Aoun, S. M., Shahid, S., Le, L., \& Packer, T. L. (2013). The role and influence of 'Champions' in a community-based lifestyle risk modification programme. Journal of Health Psychology, 18(4), 528-541. https://doi.org/10.1177/1359105312449194

Bateman, L. B., Fouad, M. N., Hawk, B., Osborne, T., Bae, S., Eady, S., ... Schoenberger, Y. M. (2017). Examining neighborhood social cohesion in the context of community-based participatory research: Descriptive findings from an academic-community partnership. Ethnicity \& Disease, 27 (Suppl 1), 329-336. https://doi.org/10.18865/ed.27.S1.329

Boeing, H., Bechthold, A., Bub, A., Ellinger, S., Haller, D., Kroke, A., . . Watzl, B. (2012). Critical review: Vegetables and fruit in the prevention of chronic diseases. European Journal of Nutrition, 51(6), 637-663. https://doi.org/10.1007/s00394-012-0380-y

Booth, J. M., Chapman, D., Ohmer, M. L., \& Wei, K. (2018). Examining the relationship between level of participation in community gardens and their multiple functions. Journal of Community Practice, 26(1), 5-22. https://doi.org/10.1080/10705422.2017.1413024

Ceptureanu, S. I., Ceptureanu, E. G., Luchian, C. E., \& Luchian, I. (2018). Community based programs sustainability. A multidimensional analysis of sustainability factors. Sustainability, 10(3), 870. https://doi.org/10.3390/su10030870

Egli, V., Oliver, M., \& Tautolo, E-S. (2016). The development of a model of community garden benefits to wellbeing. Preventive Medicine Reports, 3, 348-352. https://doi.org/10.1016/i.pmedr.2016.04.005

Firth, C., Maye, D., \& Pearson, D. (2011). Developing “community” in community gardens. Local Environment, 16(6), 555-568. https://doi.org/10.1080/13549839.2011.586025

Glover, T. D., Parry, D. C., \& Shinew, K. J. (2005). Building relationships, accessing resources: Mobilizing social capital in community garden contexts. Journal of Leisure Research, 37(4), 450-474. https://doi.org/10.1080/00222216.2005.11950062

Hartwig, K. A., \& Mason, M. (2016). Community gardens for refugee and immigrant communities as a means of health promotion. Journal of Community Health, 41(6), 1153-1159. https://doi.org/10.1007/s10900-016-0195-5

Haynes-Maslow, L., Osborne, I., \& Jilcott Pitts, S. B. (2018). Best practices and innovative solutions to overcome barriers to delivering policy, systems and environmental changes in rural communities. Nutrients, 10(8). https://doi.org/10.3390/nu10081012

Hsieh, H.-F., \& Shannon, S. E. (2005). Three approaches to qualitative content analysis. Qualitative Health Research, 15(9),1277-1288. https://doi.org/10.1177/1049732305276687

Lanier, J., Schumacher, J., \& Calvert, K. (2015). Cultivating community collaboration and community health through community gardens. Journal of Community Practice, 23(3-4), 492-507. https://doi.org/10.1080/10705422.2015.1096316

Leung, C. W., Hoffnagle, E. E., Lindsay, A. C., Lofink, H. E., Hoffman, V. A., Turrell, S., ... Blumenthal, S. J. (2013). A qualitative study of diverse experts' views about barriers and strategies to improve the diets and health of Supplemental Nutrition Assistance Program (SNAP) beneficiaries. Journal of the Academy of Nutrition and Dietetics, 113(1), 70-76. https://doi.org/10.1016/j.jand.2012.09.018

Macias, T. (2008). Working toward a just, equitable, and local food system: The social impact of community-based agriculture. Social Science Quarterly, 89(5), 1086-1101. https://doi.org/10.1111/j.1540-6237.2008.00566.x

Maxwell, A. \& Miller, B. A. (2008). Categorizing and connecting strategies in qualitative data analysis. In S. N. HesseBiber and P. Leavy (Eds.), Handbook of emergent methods (p. 461-477). New York: Guildford Press.

McCormack, L. A., Laska, M. N., Larson, N. I., \& Story, M. (2010). Review of the nutritional implications of farmers' markets and community gardens: A call for evaluation and research efforts. Journal of the Academy of Nutrition and Dietics, 110(3), 399-408. https://doi.org/10.1016/j.jada.2009.11.023 
Parry, D. C., Glover, T. D., \& Shinew, K. J. (2006). "Mary, mary quite contrary, how does your garden grow?": Examining gender roles and relations in community gardens. Leisure Studies, 24(2), 177-192. https://doi.org/10.1080/0261436052000308820

Patel, I. C. (1991). Gardening's socioeconomic impacts. Journal of Extension, 29(4), 7-8. Retrieved from https://www.joe.org/joe/1991winter/a1.php

Patton, G. B. (2009). Exploring the leadership styles of community-based early childhood education program directors (Doctoral dissertation). Retrieved from ProQuest Dissertations \& Theses Global. (Order No. 34480802).

Quested, E., Thøgersen-Ntoumani, C., Uren, H., Hardcastle, S. J., \&, Ryan, R. M. (2018). Community gardening: Basic psychological needs as mechanisms to enhance individual and community well-being. Ecopsychology, 10(3). https://doi.org/10.1089/eco.2018.0002

Short, A. (2012). Planning the seeds of university community gardens: Leadership and management techniques for 'living laboratories' of sustainable campus and community development (Master's thesis). Retrieved from http://hdl.handle.net/1993/8848

SNAP-Ed Toolkit. (n.d.). ST6: Champions. Retrieved August 20, 2019, from https://snapedtoolkit.org/framework/components/st6/

Teig, E., Amulya, J., Bardwell, L., Buchenau, M., Marshall, J. A., \& Litt, J. S. (2009). Collective efficacy in Denver, Colorado: Strengthening neighborhoods and health through community gardens. Health \& Place, 15(4), $1115-1122$. https://doi.org/10.1016/j.healthplace.2009.06.003

U.S. Department of Agriculture Food and Nutrition Service [USDA FNS] (n.d.). Supplemental Nutrition Assistance Program Education (SNAP-Ed). Retrieved February 19, 2019, from https://www.fns.usda.gov/snap/supplemental-nutrition-assistance-program-education-snap-ed

Whatley, E., Fortune, T., \& Williams, A. E. (2015). Enabling occupational participation and social inclusion for people recovering from mental ill-health through community gardening. Australian Occupational Therapy Journal, 62(6), 428437. https://doi.org/10.1111/1440-1630.12240 